\title{
Social Influence Data Analytic For Supply Chain Management in Fashion Industry
}

\author{
Puspita Nurul Sabrina ${ }^{1}$, Fajri Rakhmat Umbara ${ }^{2}$, Herdi Ashaury ${ }^{3}$ \\ \{ puspitasabrina14@gmail.com ${ }^{1}$,fajri.umbara@lecture.unjani.ac.id ${ }^{2}$, \\ herdi.ashaury@lecture.unjani.ac.id ${ }^{3}$ \} \\ Universitas Jenderal Achmad Yani ${ }^{1,2,3}$
}

\begin{abstract}
Supply chain management in the area of fashion is a flow that is interconnected from upstream which is a supplier of fashion production to the downstream who are users of fashion products. In the downstream data of customer experience is one of the concepts (use case) which avoids out of stock as a competitive advantage factor. The analytic data process involves various entities in line with the massive growth of electronic commerce and social media which provides a social influence on customer purchases. Data analysis requires relevant data and data resources of customer activities and trends and appropriate methods to produce effective knowledge for the needs of the supply chain process in the midstream and downstream. This research produces an architectural model that describes the objectives, data/data resources and relevant methods used in the analytical data process of social influence on the supply chain of the fashion industry.
\end{abstract}

Keywords: Social Informatics, SCM, Fashion, Data Analytics

\section{Introduction}

Nowadays SCM as data/information-driven business, an existing concept show that customer experience is one of the concepts (use case) which avoiding out of stock as a competitive advantages factor. Customer experience has some attributes such as Customer loyalty, Precise Customer Segmentation, Interactive and integrated customer services, bussiness of scale and/or "push/pull" bullwhip effect [1].

Those attributes collected from many resources. We see that online trading like ecommerce, online marketing can be part of the attributes. We want to map the possible sources of data. Then we investigate methods related to the analytic process to meet social influence factors, downstream activity, and supply chain activities.

Several opportunities arise with the development of social media and electronic commerce that is related to social influence because the fashion world touches on individual aspects that are deeply affected by social influences that we can think of as trends. Departing from this trend becomes an input for data flow from downstream to upstream which affects the supply chain.

A literature review, consist of content analysis of 45 articles with peer-reviewed journals, and proposed a extensive map that integrates the latest uncovering on socially connected implementations in the textile/clothing industry with intense conceptualizations to reveal areas of prospective research in the area. The conclution of the review show a lack of ongoing 
investigations concerning the social dimensions of the triple basis layer in SSCM. The inventions indicate that the industry's internal orientation is the primary companion aspect in sustainable supply chain management implementations [2].

The appearance of social trade has involved major transformations to business and consumers. Therefore, understanding users behavior in the conditions of social trade has become important for corporations that aim to persuade consumers better and exploit the strength of their social ties. This issue is novel and is mainly fragmented, it will be literally significant to assest what has been learned and obtain valuable insights through arranged reviews of the literature. In the previous work, conducted a systematic analysis of social commerce research to explain how users behave on social networking sites [1]

Previous research shows that corporate social networking has become an significant ways for marketing socialized companies, forming new challenges for enterprise on how to appeal customers. Based on theories such as buyer involvement, shared worth creation, and relationship trading. A model of the affect of customer involvement on rigidity. 260 questionnaires collected from microblog consumers of the Sina Company were analyzed and elaborate by structural equation modeling. Empirical results explain that customer involvement has actual and positive impact on customer rigidity and indirect impact over customer benefit creation. This study improves previous research on available theories about customer involvement, shared value creation, and rigidity, and provides practical direction for enterprises to promote buyers engagement and increase the rigidity of corporate social networks [2].

In this study, the analytical data model will be used to get consumer tendencies. An analytical data model concept will be proposed which will utilize social influence factors to find out the trends of society in the fashion world. The related data will be analyzed and processed so as to produce a knowledge of the tendency and trend of society in certain fashion. By the knowledge that will be obtained can be referenced in determining an effective production plan and inventory plan.

\section{Method}

This research using scientific methods that carry out the three steps. First, analysis with narrative and systematic review approach. The second is modeling uses the Architectural Desain approach. The last one is Model Evaluation used review checkpoint on a variable, contradicting part, relation input and output and series of models.

\subsection{Analysis and Review of Data Sources}

Data sources can be derived and obtained from the various application. Social media and social networking data [4]. Sales history data [5], Benefiting from brand society initiatives and the prospective benefits of social media can be one of the sources. The other source related to the history of activity fashion industry likes transaction and production. We also analyze and review various aspects and variety of data, such as words, locations, nature's components, and human behavior.

Social media data like status updates from Social Media like Facebook and Twitter were the most general source, blogs, review or comment and discussion forum, the selling and marketing of products and services in online communities and marketplaces. Relates to social 
influence, social commerce with social media sites, such as Facebook, Instagram, Twitter which contribute user-generated content and social interactions. Social trade as the "exchangerelated activities in computer and smartphone media in social environments that take place in, or are impacted by an personal's social network. The activities related to the need recognition and identification, pre-purchase order, Purchase order, and post-purchase or aftersale stages. This definition explains two constraction blocks of the concept: (1) exchange-related activities, that consist of various staps of consumers' decision making; and (2) electronic social environments, where meaningful individual connections and sustained social activities happens among network participants in Yadav et al from [3]. Based on the data sources above, we classify data sources into 3 groups, namely data sources from realtime applications, then data sources from IT-based supply chain management activities and other data aspects such as those related to demographics.

\subsection{Analysis and Review Methods}

\subsubsection{Big Data and Machine Learning}

The colaboration of big data technology and machine learning methods has produced novel and fascinating challenges in other fields as social media and social networking. These new challenges focus primarily on some problems like data processing, data storage, data representation, and how to use data to mine patterns, analyze and elaborate user behavior, and visualize data. Then presents a revision of a new methodology designed to enable efficient mining of data and the incorporation of information from social media and from new applications and frameworks that nowadays appear below the "umbrella" of social networks, social media and the big data paradigm [3]. The purchasing pattern can be used by the marketing department to build an optimal marketing strategy [4].

One of the SC Operations and Management is related to data/information-driven is the Customer Experience whose competitive advantage is social influence and analysis for customer retention and efforts to avoid the condition of "out of stock" for customer satisfaction. The attributes needed are customer loyalty, appropriate customer segmentation for the optimal approach, interactive and integrated customer service, economies of scale and/or "push/pull" bullwhip effects. A deep understanding of data, in this case, is big data using fundamental technology that is closely related to big data processing including Cloud Computing, IoT, master database management system (MDMS), Apache Hadoop, Apache Spark, Map-Reduce, etc [5]. The use of Hadoop technology can improve efficiency in methods to find patterns such as the Prefixspan method [6].

There are saveral analytical techniques such as data mining, statistical analysis, visualization, and machine learning. Many research deal with this field by improving the techniques, proposing new techniques or testing combinations of algorithms and technologies. Thus, Big Data encourages the development of system architecture, hardware and software. However, need analytical progress to deal with the challenges of Big Data and stream processing. One problem is how to guarantee a timely response when the data volume is very large [7].

A large number of researches on sustainability in supply chain management has been carried out by academics over the past decade. Socially related aspects are still ignored in related discussions. Focusing typically on social release in sustainable supply chain management (SSCM) taking into account the textile sector as an application area [8]. 


\subsubsection{Social Computing}

Benefiting from brand society initiatives and the prospective benefits of social media, many marketing invest heavily in building brand society based on data from social media. It is important to understand how the brand-based social media community affects customer perceptions and behavior. Model various aspects of customer relations with the community influence their perceptions and behavior describe customers with brands that influence the relationship with elements of brand community, mark brand community, and at last the quality of brand relationships and brand loyalty. The experiment using a large data sample of brand community members on social media and using structural equation modeling, the result is estimation how much the social media-based brand community influences the quality of brand relationships and brand loyalty and how about influence of managerial implications [9].

Successful supply chain management needs to involve functions of managing personal activities to integrate into the main supply chain processes. The textile and garment industry implementation today has differences which the supply chain that driven by buyers led by multinational companies now change to the garment industry that supply-based commodity chain led by a combination of retailers, contractors, subcontractors and merchandisers.

Buyers and suppliers, each do an important part in supply chain networks that stretch from fiber to yarn, to fabric, to accessories, to garments, to trade and marketing. Geographically they reach a lot of content and cross-regional and national boundaries. The supply chain of textile industry involves new function those are product design and development kind of material, development product manufacturing, improvement product distribution, and product sales. The product design phase have to involve customers to define what actually they need and satisfy their requirements appropriately.

The benefits are far more than the means to involve in accessing end products, unlimited chains that operate smoothly and benefit the entire value chain by accelerating communication between customers and their suppliers, reform service quality, and reducing expense [10]. Social commerce via social media or social networking platforms has conduct to the development of new business or industry models in e-commerce and digitizing the journey of consumer decisions. Social interaction is respected a precondition for successful social commerce because buyers now expect interactive and social experiences when making purchasing decisions. Word of mouth (WOM) and observational learning theory, we constracted social interaction in a social trading environment into two forms: WOM communication and observing other consumer purchases, and testing their effect on consumer purchase intentions and proper buying behavior. Analyzed primary sample $(n=217)$ collected from active consumers surveyed in social commerce websites in two phases (pre-purchase and post-purchase), found that WOM was positive and negative valence, WOM content, and observed other consumer purchases significantly affects consumers' motive to buy a product, thereby increasing the possibility of factual purchases and sharing product information with others on social trading websites [11].

A promising field of research in the area of decision groups (GDM) is the research of interpersonal influences and their influence on the evolution of the opinions of experts. In conventional GDM models, a group of experts declared their preferences in a limited set of alternatives, then the preferences are collected and the best alternative, which satisfies the majority of experts, is chosen. In actual situations, experts shape their opinions in complicated interpersonal environments where preferences tend to change due to social influences. Considered the impact of social influence and impact during the GDM activities, a novel 
influence-guided GDM model establish on the assumptions: experts influence each other and the more experts trust other experts, the more their opinions are impacted by that expert.

The effect of social influence is very relevant to cases when due to the complicated of the domain, limited expertise or pressure to take decisions, an expert cannot express preferences in several alternatives, that is, in the existence of incomplete information. The model adopts fuzzy ratings to gather the preferences of both experts on existing alternatives and statements of trust in other experts. Begin from the information gathered, it may be incomplete, the configuration and power of interpersonal influence are evaluated and reflected through social influence networks (SIN). SIN, in turn, is used to estimate lost preferences and develop them by simulating the effects of expert interpersonal influences before combining them for the selection of the best alternatives. The model has experimented with compositive data to show the impact driven by the evolution of opinion and the nature of convergence [12].

The model of cultural influence produces more different cultural zones once the grid has reached equilibrium. The Axelrod balance state of the model is consistently decreased on a larger grid of six agents by six agents. The social influence model requires more time to achieve balance when compared to the original Axelrod model. This is because, in part, each agent is between different cultural countries compared to the original model. In Axelrod's models, orders increase linearly, while our Social Influence Model experiences assumption of agents that are initially fast are followed by convergence that is slower to a state of equilibrium. The various measures of our heterogeneity in equilibrium conditions also show a higher-end disorder for the Social Influence Model. We found that for both models, agents in the middle of the grid experienced the most interaction, with a decrease in the number of interactions per agent closer to the edge of the grid. This effect is more prominent in the Social Influence Model. This shows the "freezing" of cultural areas that spread inward towards the edge, with a hard boundary of cultural zones becoming a catalyst for regional formation.

Social computing is a multi-disciplinary studies and application area with literally underpinnings consist of both computational and social sciences [13]. Big Data Analytics is Big Data goes far beyond the increasing quantity and quality of data and focuses on intelligent decision-making analysis. Independent from the certain Peta-, exa-, or zettabytes scale, the key attribute of the paradigmatic transformation is that analytic usage of data is systematically placed at the forefront of intelligent decision-making [14]. The main objective of persuasive software patterns was to increase generalizable techniques that could help the development of social support features in many persuasive system [15].

\section{Result and Discussion}

SCM (Supply Chain Management) in this study focused on the downstream with customers, resellers, merchandisers as parts. The information of them can encourage increased effectiveness and efficiency in the inventory and production field by capturing properly what is needed by consumers. Consumers integrated into the supply chain process which gets involved in product design. Data analytics of social influence results in customer trends and tendencies. The company is also expected to avoid "out of stock" conditions. To produce products that are in accordance with consumers' demands, they can be involved in the product design process.

The fashion industry is one of the global industries in the world today so that informative and data-oriented strategic decision making, especially with regard to the social dimension is 
very necessary. Social issues, among others, in sustainable supply chain management (SSCM) by considering the textile/clothing field to be a growing application field. How the social media-based brand community influences customer insight and behavior, brand relationship quality and brand loyalty, the product design phase must involve customers to explain and meet their needs. Successful supply chain management requires changes in individual management to be integrated into the main supply chain processes, with the aim of accelerating communication between customers and suppliers.

Integrating between SCM and social influence can be implemented with social computing is a multi-discipline study and application area with underpinnings consist of both computational and social sciences.

ICT collaboration consists of several activities such as Collaborative Design, Management of Capacity Inventories by online, logistics support by online, some modern practices concepts like e-business market exchanges, e-collaborative market places. Capitalize customer feedback and turn it into innovation. Embed some value in the product. Used collaborative planning and Forecasting and Replenishment (CPFR).

Related to vendor needs Vendor Managed Inventory (VMI), Online network and connections for POS or EPOS will support the internal company transfer of data, information and other business documents. Realtime Application like Social Media, Position/Map and Payment Gateway. Online marketing, e-commerce dan website is a medium that is very often used in the fashion field. promotions through various social media managed to increase sales. Data can be extracted from Demographic aspects like Age, Gender, Education Level, Age of e-commerce users, frequency online purchase, money spent online.

We use conceptualize social interaction in a social trading environment into two ways: WOM (Word-of-mouth communication) communication and observing consumer purchases, and testing their influence on consumer buying intentions and actual buying behavior. The impact of social influences are very relevant to cases when, due to the complexity of the domain, limited expertise or pressure to make decisions, an expert cannot express preferences on several alternatives, that is, in the presence of incomplete information. On the other hand, we used a model of cultural influence that produces more different cultural zones.

Technology that apply in Social influence adopt the researches that encourages researchers to follow a multi-theoretical understanding of social influences on user interfaces, social references, and technology.

Social Commerce is proposed to the combination of trading and social networking processes. We can see impact of buyer behavior and buying decisions. Besides that, we can add Web of Science database to produce recommendations, referral mechanisms, ratings and reviews. We need to predict the desire of costumer used to predict individuals' purpose to engage in social commerce, from that can establish new social relationships on social media platforms.

Persuasive systems also we choose as one of process data analytics. This concept enables buyer to express themselves thus tapping into the deep-rooted human expected for expression and interaction. It produces Software pattern features, first social learning behavior and facilitation (SLF) to learn the activity of buying, the trend model, color, etc. Second Competition (COM) to watch how competition between fashion companies. Cooperation (COO) can describe how fashion business people work together and collaborate to get known and mutually beneficial to each other. Recognition (REC) used to get the essence of social activities, especially those related to product selection, product development, product popularity, product models, types, colors and even popular materials. 


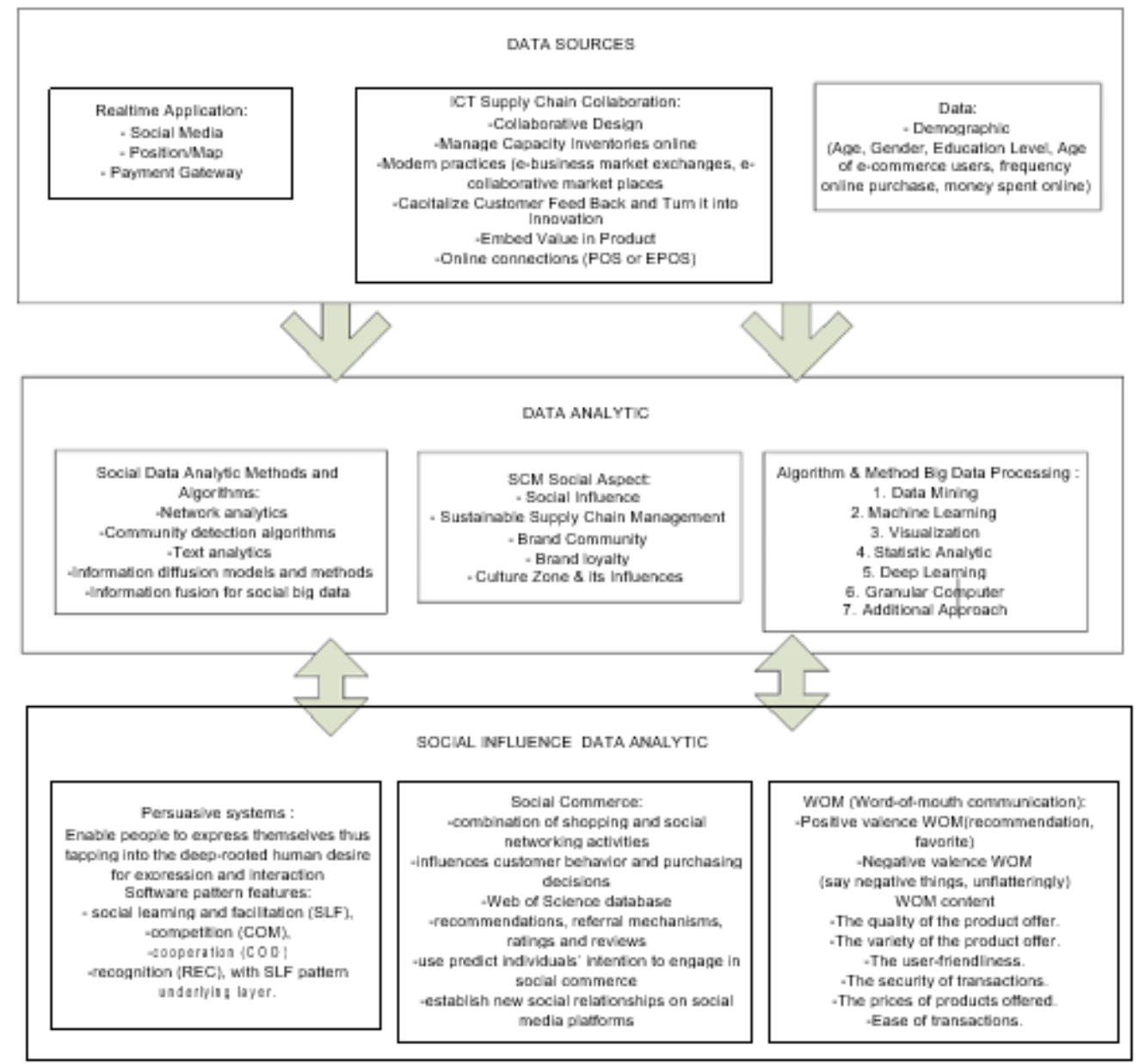

Fig. 1. Social Influence Analytical Data Model in the Fashion Domain.

The model in Figure 1 shows three layers of data analytic process. The first layer represents data sources to analyze several feature (aspects) and a variety of data, such as words, transaction, production, locations, nature's elements, and human behavior. Data source from social media that used online postings in blogs, media, and web pages. Social media data consists of status updates from media social application such as Facebook and Twitter, Blogs, review and discussion forum. The second layer represents the method of Social Data Analytic Methods and Algorithms covers heterogeneous diffusion model (Inter-Project Social Network, Social Proximity). Social Influence Locality, Sampling Near Neighbors, Neural Network Model, Agent-based social modeling. The last layer explains social influence covers. Persuasive systems that Enable costumers to declare themselves thus tapping into the deeprooted human intended for expression and interaction Software pattern features - social learning and facilitation (SLF), competition (COM), cooperation (COO), recognition (REC), with SLF pattern underlying layer. Social Commerce: the combination of shopping and social networking activities, influences customer behavior and purchasing decisions, Web of Science 
database, recommendations, referral mechanisms, ratings and reviews, use predict individuals' intention to engage in social commerce, establish new social relationships on social media platforms. WOM (Word-of-mouth communication): Positive valence WOM (recommendation, favorite), Negative valence WOM (say negative things, unflatteringly), WOM content, the quality of the product offer, the variety of the product offer, The userfriendliness., The security of transactions. The prices of products offered. Ease of transactions.

The social process data analytic on SCM starts from determining the objectives of SCM in the downstream section such as Individual integrated into the main supply chain processes, Customer involvement in product design, Customer segmentation and Interactive and integrated customer service. Furthermore, a collaboration that already exists between Supply Chain and Information and Communication Technology produces features such as Collaborative Design, Manage Capacity Inventories online, online Logistics Support, Modern practices (e-business market exchanges and e-collaborative market places Capitalize Customer Feed Back and Turn it into Innovation.

These features are combined with features that come from Realtime Applications such as Social Media, E-Commerce and E-Business and individual-related data such as demographic data. The output of the application or concept one of them produces data that is possible in a size that is large enough. The data is then processed with social data analytical techniques.

The method used is a method in big data such as Data Mining, Machine Learning, Visualization, etc. and process social data analytical methods as the basic method. Then added with new concepts such as Persuasive systems, Social Commerce and WOM (Word-ofMount).

\section{Conclusion}

Analytical data based on social influence in the fashion industry is modeled in an architecture consisting of Data/Data Source layer and Analytic Process Layer. The Process Layer is divided into a process of analytic data and analytic social influence data. A review of the narrative approach based on the study of literature and some analysis process is implemented to determine the contents of each layer. The analytic data process is carried out by taking data from various sources such as purchasing operational data, demographic data, data from various online media. The analytical process is proposed using several techniques/concepts such as Big Data, Social Analytical Data, Persuasive Systems, Social Trading and WOM (word of mouth communication). We collaborate various techniques with various data sources to form analytical data models in the downstream section so as to gain knowledge that supports making and recommendations for design products in the midstream section and material procurement in the upstream section.

\section{References}

[1] G. Bello-Orgaz, J. J. Jung a D. Camacho.: Social big data: Recent achievements and new challenges, “Information Fusion, pp. 1-15, 2015.

[2] P. N. Sabrina.: Penerapan Sequential Pattern Mining pada Data Pemesanan untuk Strategi Penawaran dan Pemasaran Produk Dengan Pendekatan Metode PrefixSpan," Palembang, 2016. 
[3] R. A. Tengkorang a P. Helo,: Big Data Applications in Operations/Supply-Chain Management: A Literature Review, “Finland, 2016.

[4] P. N. Sabrina a G. A. P. Saptawati.: Multiple MapReduce and derivative projected database: New approach for supporting PrefixSpan scalability,"Yogyakarta, 2015.

[5] A. Oussous, F.-Z. Benjelloun, A. A. Lahcen a S. Belfkih.: Big Data technologies: A survey,“ Journal of King Saud University -Computer and Information Sciences, pp. 431-448, 2018.

[6] D. Köksal, J. Strähle, M. Müller a M. Freise.: Social Sustainable Supply Chain Management in the Textile and Apparel Industry-A Literature Review,“Sustainability, zv. 9, \%1. vyd.1, 2017.

[7] M. R. Habibi, M. Laroche a Marie-OdileRichard.: Testing an extended model of consumer behavior in the context of social media-based brand communities, "Computer and Human Behavior, Elsevier, zv. 62, pp. Pages 292-302, 2016.

[8] G.Nijaguna a P. K. M.: Millennium Development in Textile Garment Supply Chain Through Information and Communication Technology,“2016.

[9] Y. Wang a C. Yu.: learning, Social interaction-based consumer decision-making model in social commerce: The role of word of mouth and observational,“ International Journal of Information Management, zv. 37, \%1. vyd.3, pp. 179-189, 2017.

[10] N. Capuano a dkk.: Fuzzy Group Decision Making With Incomplete Information Guided by Social Influence," IEEE Transactions on Fuzzy Systems, 2018.

[11] F.-Y. Wang a D. Zeng.: Social Computing: From Social Informatics to Social Intelligence," rev. IEEE Computer Society, California, 2007.

[12] M. Hilbert.: Big Data for Development: A Review of Promises and Challenges,“ Development Policy Review, zv. 34, \%1. vyd.1, pp. 135-174, 2016.

[13] M. Oduor, T. Alaha“iva"la“ a H. Oinas-Kukkonen.: Persuasive software design patterns for social influence," rev. Springer, London, 2014. 